been opened up in connexion with methods of counting the fundamental particles of Nature, and in problems relating to radioactivity in general; several instruments for such purposes were exhibited. The widening needs of the radio engineer were also catered for in such items as standard-signal generators, field-intensity meters, valve voltmeters and oscil. lators of various types. The influence of television and frequency-modulation broadcasting has resulted in the production of a television sweep generator covering the frequency-range 40-190 Mc./s., a frequency-modulation receiver tester for the range 21-168 Mc./s., and also a carrier-deviation meter having a signal carrier range of 4-250 Mc./s., with deviation ranges of $0-5,0-25$ and $0-75 \mathrm{kc} . / \mathrm{s}$. The continued success and popularity of this symposium and exhibition should do much to assist the development and application of electronic techniques of all types.

\section{THE BRITISH HAT AND ALLIED FELTMAKERS RESEARCH ASSOCIATION}

\author{
By DR. T. BARR \\ Director of Research
}

$\mathrm{F}^{\mathrm{T}}$ LTMAKING as a textile industry preceded the manufacture of woven fabrics. In England, it has been an established craft for some centuries, with the Worshipful Company of the Art or Mistery of Feltmakers, a Livery Company of the City of London, controlling its destiny. This Company was granted its first Royal Charter in 1604 ; but records show that the industry was in existence for at least a hundred and fifty years prior to that date. With such a traditional background, there has been a natural reluctance to change. In addition to this aversion to change, the feltmaker, until recently, has closely guarded his secrets and processes from his neighbour, who was virtually his only competitor.

The pressure of outside events, however, has resulted in a revolution of ideas within the industry, culminating in the formation of the British Hat and Allied Feltmakers Research Association, the laboratories and headquarters of which at Stanley House, Fairfield, Manchester, were formally opened on September 19 by the Earl of Derby.

The change in the attitude of the industry which led to co-operation in the solving of its common problems was clearly expressed by Col. J. A. ChristieMiller (president of the British Felt Hat Manufacturers' Federation), who said : "As a result of two world wars, the opening of new factories in many countries, the installation of new machinery which is largely automatic and does not require skilled men to work it, and because of trade barriers and import restrictions, our competitors to-day are largely overseas." He pointed out that the industry's roughand-ready methods are no longer adequate if it is to compete in world markets. It must make the fullest use of the scientific knowledge available and apply it to meet the specialized needs of the industry.

Attempts to form a research association for the hat and felt industry date back some thirty years; but it was not until 1943 that any real interest was displayed. Then the efforts made by a small research committee of the Worshipful Company of Feltmakers resulted in laying the foundations for the present organization. The response by firms engaged in the industry surprised even the sponsors of the scheme, whose hopes at the most were centred on securing enough funds to promote one or two research projects in existing laboratories. Once the benefits to be derived from the application of scientific methods in solving the long-standing technical problems of hat and felt manufacture had been appreciated, sufficient support was received from various branches of the industry and associated trades, and it was found possible to make immediate plans for establishing a felt research centre.

The Research Association was incorporated in February 1947, and recognized by the Department of Scientific and Industrial Research shortly after, being given the same status as other similar organizations with a substantial grant from Government funds, based on the income derived from the industry. In the same year, the first technical appointment was made, and the work of equipping laboratories and initiating a research programme was begun. Experimental work was started in 1948 in temporary quarters in the University of Leeds, where a laboratory was rented from the Department of Textile Industries. Although space was limited, the freedom to use the equipment and library facilities available at the University was of inestimable value in the early days of the Association while a permanent home was being found and equipped.

The research programme of the Association is decided and controlled by three research committees, representing the three main sections of the industry, producing wool felt, fur felt and hatters' fur respectively.

The initial programme took full cognizance of the fact that the industry, having developed by empiricism and reliance on rule-of thumb methods, was lacking in quantitative methods of assessing progress. Therefore, the physical properties of felt are being studied in the hope that tests will be evolved as yardsticks for the trade. Arising from this study, a scheme for the quality control of felt has already been worked out which separates 'bulk' properties from 'fibre' properties. This scheme has found many applications and has provided members of the Association with the means of measuring changes in the quality of felt resulting from the modification of manufacturing procedure; and at the $\operatorname{sam} \theta$ time it has made it possible to determine whether or not the fibres from which the felt is manufactured have undergone any degradation during processing. In measuring the tensile properties of the felt, which forms an essential part of the scheme, it was discovered that the shape of the load-extension curves of the test samples is related to the previous history of the felt. The full significance of this discovery is demonstrated by the fact that it has repeatedly been used for solving 'blocking' problems of hat manufacturers.

The research projects also include studies such as that of the 'carrotting' process-the preparatory chemical treatment for rabbit and other furs, without which they lack the requisite properties for felt manufacture. A fundamental study of carrotting was begun in order to elucidate the chemistry of the reactions and the mechanism of the changed felting properties arising from the treatment. Considerable advances have already been made in this line of research. and 
a better understanding has been reached of the chemical groups of the fur molecule which take part in the reaction. As a result, there is a prospect of the early development of a reliable test for the degree of carrotting of fur.

In the field of technological research, the staff of the Association is engaged in studying the different processes in the manufacture of felt from both wool and fur. Felting of these animal fibres is carried out in an acid modium, sulphuric and phosphoric acids being normally used for the purpose. Arising from work carried out by the Association in the industry, recommendations for the control of acid additions have been made and have been adopted with advantage by a number of member firms.

Further research projects of immediate benefit to the industry cover other processes such as dyeing and proofing. With the occupation of the new laboratories and the increase in staff thus made possible, widening of the scope of the programme is envisaged.

The building houses a chemistry laboratory physics laboratory ; dark room for optical and photographic work ; and a testing laboratory for operations at controlled temperature and humidity. The addition of a technological block for carrying out small-scale industrial operations has been planned, and an early start on this project is expected.

Although the industry is not a large one and most of the firms are of the small 'family' type, it makes a useful contribution to the national economy. It is gratifying to note that the hatters' fur manufacturers, who supply the raw material for the fur felt section, are solidly in support of the research association, and that the majority of hat felt manufacturers in Great Britain are members, while manufacturers of machinery and dyestuffe and ancillary trades are strongly represented.

\section{BATTERSEA LABORATORIES OF THE BRITISH IRON AND STEEL RESEARCH ASSOCIATION}

$T$

HE British Iron and Steel Research Association celebrated the third anniversary of the official opening of its Physics Laboratories at 140 Battersea Park Road, London, S.W.11, by holding 'open days' on November 9 and 10 . The laboratories were originally opened by Lord Rayleigh on October 22, 1947 (see Nature, 160, 684; 1947). The 'open days' were planned to indicate that during these three years a number of researches have led to results either having direct practical application in the steel industry or throwing light on the fundamental problems connected with iron-and steel-making and therefore of indirect value. The general plan of the Research Association under its director, Sir Charles Goodeve, is to have six Divisions (Iron Making, Steel Making, Steel Castings, Mechanical Working. Plant Engineering and Metallurgy) directly concerned with the six main groups of processes in the industry, and two Departments, Physics and Chemistry, which serve the requirements of all the six divisions. The laboratories at Battersea house the whole of the Physics Department (under M. W. Thring), a purt of the Chemistry Department (under Dr. J. Pearson) and the Electrical Engineering Section of the Plant Engineering Division (under H. H. Mardon).

\section{Physics Department}

A booklet entitled "Physics in the Iron and Steel Industry" describes the work of the B.xttersea laboratories of the Research Association and also contains short accounts from seven big steel companies of the use of physics in their laboratories. These accounts show how the increase of efficiency and reduction of wastage in an industry causes a steady growth in the reliance upon accurate instruments for measurement, control and investigation of untoward occurrences. For this reason also, one of the five sections of the Physics Department is entirely devoted to the development of new instruments for the industry.

The physics of the various phenomena occurring in the manufacture and use of iron and steel provides the field for the work of the remaining four sections. It is clear that the present tendency among many physicists to regard the atomic nucleus as the only region of the universe which contrins new and unrevealed general laws is far from justified, and much fundamental work of the greatest interest is being done already on the physics of the strength and plastic deformation of metals. Other phenomena of equal interest to the physicist are freezing and crystal growth under various types of cooling and with various impurities in the main element, the way in which atoms find their new positions in a transformation, the mixing of two fluids, heat transfer by convection from a gas jet, luminous radiation, the production of fine droplets by fluid impingement, the movement of a liquid under the impact of a gas jet, and splashing.

The following general ideas run through much of the work described: (1) the attempt to develop equipment for observing phenomena while they are occurring rather than relying on freezing them for subsequent study, and for probing inside complex systems to measure the physical conditions; (2) the application of methods of planning experiments which have been largely developed by the agriculturists to steel-industry investigations both in the laboratory and in the works ; (3) the linking together of experiment and theory based on suitable simplifying assumptions; (4) the use of model techniques for studying systems of too great geometrical complexity for a fully mathematical treatment; (5) the application of physical techniques developed for quite other purposes to solve problems of the steel industry.

In the General Physics Section (J. Savage) the physics of the freezing of steel moving relative to a water-cooled mould surface has boen intensively studied with the view of providing the fundamental background to the crntinuous casting of steel, a process which is just coming within the range of practical industrial operation. Measurements have been made of the friction between a 21 -in. diameter mould and the freezing metal, the heat transfer through the mould and the variations in surface quality at different rates of casting and different stoel superheat temperatures. In this connexion, also, \& vacuum apparatus incorporating an Andrade balance has been built to study the plastic flnw of steel at temperatures between the $A_{s}$ point and the melting point. The flow-rate has so far been evaluated for one steel from $950^{\circ}$ to $1,400^{\circ} \mathrm{C}$. over a range of stress of $80-280 \mathrm{kgm} . / \mathrm{cm} .^{2}$. This Section has also applied the Geiger counter to the X-ray diffraction observation of transformations in steel while they occur, and to fluorescence analysis, and has developed a high. magnification, high-temperature microscope. 